\title{
PARA UMA HISTÓRIA DO PORTUGUÊS NO BRASIL E DO BRASIL: EDIÇÃO DE CARTAS SETECENTISTAS, OITOCENTISTAS E NOVECENTISTAS
}

\author{
Márcia Cristina de Brito Rumeu*
}

\begin{abstract}
Resumo: O objetivo deste trabalho é apresentar o processo de constituição dos corpora para o estudo do português no Brasil e do Brasil a partir da confecção de edições fac-similares diplomático-interpretativas de cartas manuscritas durante a $2^{\mathrm{a}}$ metade do século XVIII, ao longo do século XIX e na $1^{\mathrm{a}}$ metade do século XX. A edição das amostras de cartas que compõe o português no Brasil se dá em relação a sessenta cartas produzidas por brasileiros e por portugueses, manuscritas no Rio de Janeiro setecentista e oitocentista. No que refere à edição das amostras do português $d o$ Brasil, têm-se cento e setenta cartas familiares autógrafas confeccionadas, por brasileiros nascidos no Rio de Janeiro oitocentista, entre os anos de 1877 e 1948 , e integrantes de uma mesma família: a família Pedreira Ferraz - Magalhães.

Palavras-chave: Crítica textual; edição de missivas manuscritas; português no Brasil; português $d o$ Brasil.
\end{abstract}

\section{Considerações iniciais}

A análise da configuração da norma brasileira do português está condicionada à edição de corpora confiáveis aos

* Universidade Federal de Minas Gerais. 
estudos linguísticos de sincronias passadas. Nesse sentido, põese em discussão, neste trabalho, o processo de constituição de corpora representativos da língua portuguesa no Brasil dos séculos XVIII e XIX e da língua portuguesa do Brasil dos séculos XIX e XX.

Barbosa,${ }^{1}$ ao afirmar que "ao estudo da sociedade americana falante do Português enquadra-se a questão do Português $d o$ Brasil, ao passo que, ao estudo da língua da comunidade europeia, corresponde a questão do Português no Brasil (...)" (itálico nosso), permite entender que a discussão acerca do português no Brasil pode se dar tanto em sentido restrito, quanto em sentido lato. Em sentido lato, a noção de português no Brasil é determinada pela especificidade diatópica (geográfica), ou seja, privilegiam-se os textos produzidos no território brasileiro, tendo em vista a impossibilidade de dispor de informações precisas acerca da nacionalidade (origem) de todos os autores dos textos. Em sentido restrito, a língua portuguesa no Brasil é reflexo da produção escrita de portugueses que residiam no Brasil em convivência com lusófonos (brasileiros) na América Portuguesa.

Considerando a distinção estabelecida por Barbosa entre português no Brasil e português brasileiro (doravante PnB e PB, respectivamente) vinculada a não identificação da origem de todos os autores de algumas das cartas setecentistas e oitocentistas (cartas oficiais e não oficiais), concebe-se também o critério geográfico como fator determinante para entender tais cartas como um testemunho escrito do que se concebe como o PnB.

Em relação às amostras de cartas oitocentistas e novecentistas representativas do $\mathrm{PB}$, apresenta-se a edição de um conjunto de cartas produzidas por integrantes da família Pedreira Ferraz-Magalhães. Trata-se de cartas familiares, muito íntimas, representativas da escrita de brasileiros cultos, em fins do século XIX e na primeira metade do século XX. O caráter inovador de tais amostras de missivas oitocentistas e novecentistas reside no fato de ter sido

${ }^{1}$ BARBOSA. Para uma bistória do português colonial, p. 14. 
possível reconstituir a ficha biográfica de todos os missivistas brasileiros (nascidos no Rio de Janeiro) unidos por laços de consanguinidade, mostrando-se, pois, como a expressão de corpora confiáveis aos estudos de base sociolinguística do PB.

Considerando o desgaste das nomenclaturas dos textos já consagradas - textos narrativos, descritivos, argumentativos e dissertativos -, Barbosa ${ }^{2}$ admite o modo de circulação do documento não-literário (itálico nosso) como critério que conduzirá, de forma mais coerente, à proposição da sua tipologia. Assim sendo, o modo de circulação dos documentos funciona como o parâmetro responsável por identificar a especificidade dos textos: os de circulação oficial - cartas da administração pública -, os de circulação privada - cartas da administração privada - e os particulares (pessoais). A busca por textos não-literários, com base na proposta de tipologia textual pensada por Barbosa,${ }^{3}$ resultou na organização das cartas manuscritas em discussão a partir dos eixos de circulação do documento - público, privado e particular. Assim sendo, acredita-se que, à luz das palavras de Barbosa, seja possível legitimar a aplicabilidade da sua perspectiva aos estudos linguísticos acerca do processo da formação do $\mathrm{PB}$, voltando-se o escopo da análise tanto para o PnB, quanto para o PB:

esta pesquisa contribui também, indiretamente, para os estudos diacrônicos do Português do Brasil: só se pode saber o que seria o Português do Brasil naquela época, se se souber o que viria a ser o Português no Brasil. ${ }^{4}$

Admite-se que, em conformidade com o pensamento de Cambraia e Lobo, ${ }^{5}$ "editar um texto consiste em escolher-se, do

\footnotetext{
${ }^{2}$ BARBOSA. Para uma história do português colonial.

${ }^{3}$ BARBOSA. Para uma história do português colonial.

${ }^{4}$ BARBOSA. Para uma história do português colonial, p. 15.

${ }^{5}$ Apud LOBO. Depoimento sobre a constituição de um corpus diacrônico do português brasileiro - Bahia, p. 179.
} 
ponto de vista formal, uma maneira particular de o divulgar, a qual será basicamente determinada a partir do público leitor que se queira atingir". Assim sendo, acredita-se que uma edição facsimilar diplomático-interpretativa de textos produzidos no Brasil dos séculos XVIII e XIX corresponda aos anseios do linguistapesquisador ávido por fontes confiáveis ao estudo da formação da norma brasileira do português.

Retome-se ainda a indagação tecida por $\mathrm{Lobo}^{6}$ sobre a edição de cartas particulares oitocentistas do Recôncavo Baiano, a fim de entender a relevância da edição de corpora para o estudo da formação do PB: "Qual a especificidade do corpus que aqui se apresenta em face de um corpus geral diacrônico para o estudo da constituição histórica do português brasileiro (...)?". Julga-se que, a partir dos textos escritos em terras brasileiras, ${ }^{7}$ seja possível contribuir para a análise da face assumida pela língua portuguesa na realidade sócio-histórica colonial e imperial do Brasil. A esses corpora que vieram elucidar o PnB, acrescenta-se a edição de sessenta cartas manuscritas no Rio de Janeiro setecentista e oitocentista, confeccionada por Rumeu. ${ }^{8}$

As palavras de Castro ressaltam inclusive a importância dos recortes temporal e diatópico na constituição de corpora para estudos comparativos entre a realidade linguística lusitana e a brasileira da língua portuguesa.

para nos sentirmos todos mais à vontade neste domínio, que interessa tanto a brasileiros como a portugueses, seria conveniente desenvolver, nos estudos lingüísticos sobre o português, uma prática de análises comparatistas

\footnotetext{
${ }^{6}$ LOBO. Para uma sociolingüística bistórica do português no Brasil, p. 109.

${ }^{7}$ Destacam-se tanto as cartas de comércio produzidas no Brasil da segunda metade do século XVIII, editadas por Barbosa (Para uma bistória do português colonial), quanto as cartas particulares do Recôncavo Baiano do século XIX, editadas por Lobo (Para uma sociolingüística bistórica do português no Brasil).

${ }^{8}$ RUMEU. Para uma bistória do português no Brasil.
} 
em que as estruturas brasileiras e portuguesas fossem, por sistema, confrontadas, para não acontecer que se afirme a diferença na ausência, ou no desconhecimento, de um dos termos da comparação. ${ }^{9}$

Em consonância com o pensamento de Castro, avalia-se positivamente a tarefa de contribuir para a composição de corpora que evidenciem o PnB, aliada a outras iniciativas que possibilitem o reconhecimento do $\mathrm{PB}$, como é o caso da edição de documentos produzidos pelos africanos e seus descendentes confeccionada por Oliveira. ${ }^{10}$ Acrescente-se ainda que, a partir de estudos comparativos entre os traços do português europeu (doravante PE) em oposição aos do PB, seja possível entrever-se, criteriosamente, a expressão brasileira da língua portuguesa.

Como evidência do PnB, editaram-se dois corpora a perfazerem um total de sessenta cartas produzidas no Rio de Janeiro - quinze cartas oficiais e quinze não-oficiais da segunda metade do século XVIII; quinze cartas oficiais e quinze não-oficiais do século XIX. Dessas sessenta correspondências manuscritas no Rio de Janeiro colonial e imperial, quarenta e uma mantêm seus originais sob a guarda da Biblioteca Nacional do Rio de Janeiro, quatro compõem parte do acervo do Instituto Histórico e Geográfico Brasileiro do Rio de Janeiro e quinze apresentam-se encerradas no Arquivo Nacional do Rio de Janeiro. Organizou-se uma edição fac-similar diplomático-interpretativa de cartas oficiais e cartas não-oficiais constituída tanto por textos autógrafos, quanto por cópias de época.

Para dar testemunho do PB, Rumeu ${ }^{11}$ editou, com fac-símile e diplomatico-interpretativamente, um total de cento e setenta

\footnotetext{
${ }^{9}$ CASTRO. Para uma história do português clássico, p. 139 apud LOBO. Depoimento sobre a constituição de um corpus diacrônico do português brasileiro - Bahia, p. 180.

${ }^{10}$ OLIVEIRA. Textos escritos por africanos e afro-descendentes na Babia do século XIX.

${ }^{11}$ RUMEU. A implementação do 'você' no português brasileiro oitocentista e novecentista.
} 
cartas familiares - dezoito cartas para fins do século XIX e cento e cinquenta e duas cartas para a $1^{\mathrm{a}}$ metade do século $\mathrm{XX}$ - manuscritas por integrantes de uma mesma família constituída somente por escreventes brasileiros. Tais cartas, produzidas por brasileiros da família Pedreira Ferraz-Magalhães estão sob a guarda do Arquivo Nacional do Rio de Janeiro, inscritas na Coleção Particular da "Irmã Zélia”.

Para a edição dessas missivas setecentistas, novecentistas e oitocentistas, assumiu-se a concepção de Spina acerca do que vem a ser uma conservadora edição diplomático-interpretativa:

a transcrição diplomático-interpretativa (ou semidiplomática) vai mais longe na interpretação do original, pois já representa uma tentativa de melhoramento do texto, com (...) o desdobramento das abreviaturas (trazendo as letras, que não figuram no original, colocadas entre parênteses) ${ }^{12}$

Os princípios norteadores da transcrição diplomáticointerpretativa das missivas setecentistas, oitocentistas e novecentistas em discussão foram estabelecidos por ocasião do II Seminário do Projeto Para a História do Português Brasileiro, ${ }^{13} \mathrm{em} 1998$, e foram divulgadas por Cunha, Cambraia e Megale. ${ }^{14}$

\footnotetext{
${ }^{12}$ SPINA. Introdução à edótica, p. 79.

${ }^{13}$ As normas para transcrição de manuscritos dos séculos XVIII e XIX foram estabelecidas no II Seminário do Projeto para a História do Português Brasileiro por um grupo de pesquisadores formado por Heitor Megale (USP), César Nardelli Cambraia (USP), Gilvan Müller de Oliveira (UFSC), Marcelo Módolo (USP), Permínio Ferreira (UFBA), Sílvio de Almeida Toledo Neto (USP), Tânia Lobo (UFBA) e Vladimir Klamt (UFSC).

${ }^{14}$ CUNHA; CAMBRAIA; MEGALE. A carta de Pero Vaz de Caminha, p. 23-26.
} 


\section{A caracterização das amostras do português no Brasil setecentista e oitocentista: as cartas de circulação pública no Rio de Janeiro}

Resgatando-se as macro-categorias textuais propostas por Barbosa, expõe-se a sua concepção sobre textos de circulação oficial para justificar a relevância de uma edição de manuscritos que também privilegie tais tipos de textos:

Devemos entender por documentos da administração colonial em circulação pública tanto aqueles de caráter deliberativo oficial, quanto os de requerimento pessoal junto à estrutura de poder, em que pelo menos um dos interessados esteja na condição de pessoa jurídica ou de representação oficial de Estado. ${ }^{15}$

Com base na categorização dos textos não-literários pensada por Barbosa, entendem-se os textos de circulação oficial como aqueles direcionados às instâncias do Poder no Brasil colônia segunda metade do século XVIII - e ao Império Brasileiro, desde 1822 até fins do século XIX.

Com o intuito de exemplificar o tipo de assunto discutido, em uma missiva de circulação pública, é possível observar, na figura 1, uma carta oficial do Conde de Resende para Dom Fernando José de Portugal versando sobre a inocência do Bacharel José de Sá Bitancourt em relação à Conjuração Mineira. Trata-se de um documento oficial e original que, por estar editado com fac-símile, permite confrontar a interpretação do código linguístico assumida pelo editor da missiva.

\footnotetext{
${ }^{15}$ BARBOSA. Para uma bistória do português colonial, p. 149.
} 


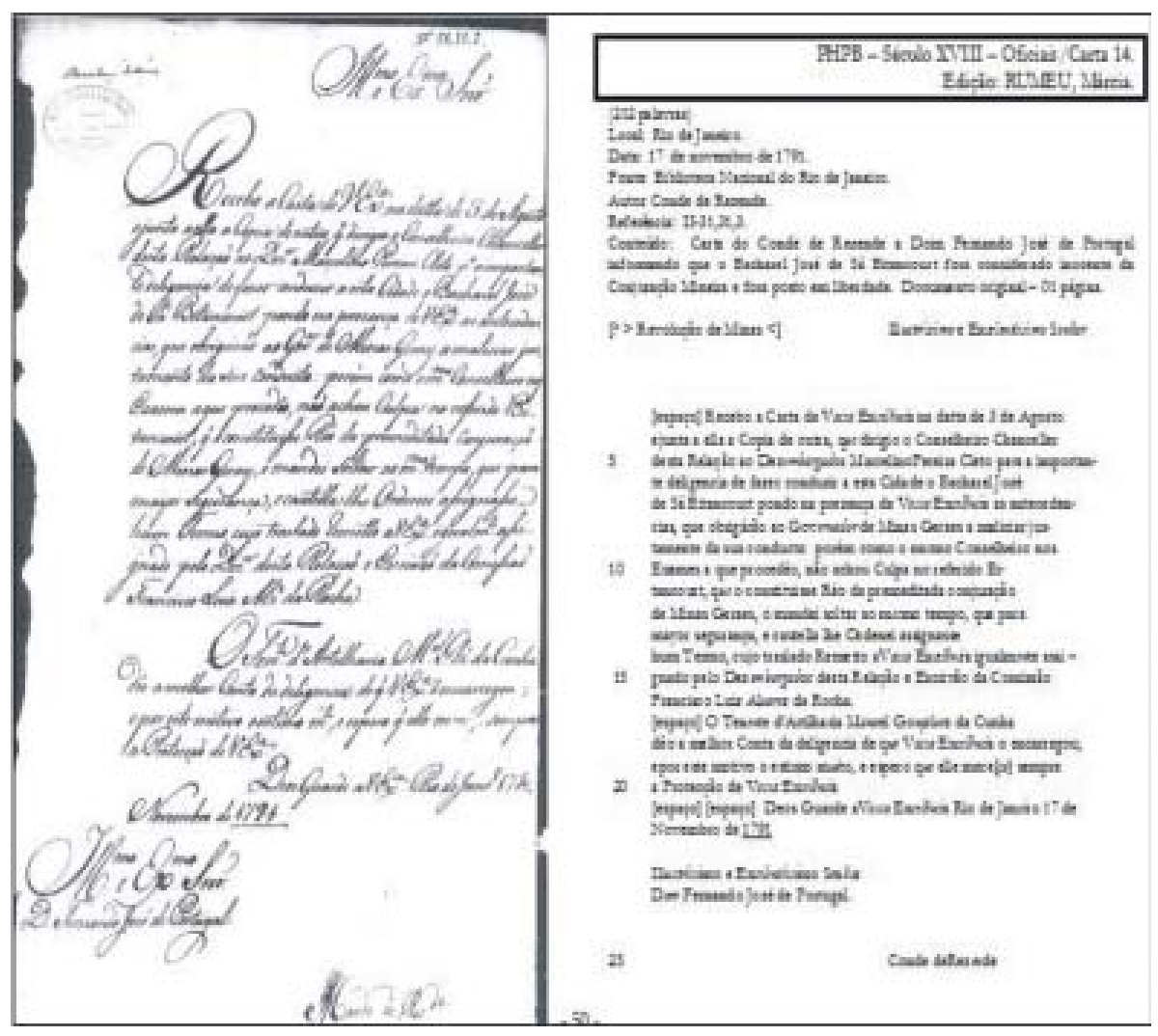

Figura 1: Carta do Conde de Rezende. Rio de Janeiro, 17.11.1791.

Acrescente-se ainda o caráter diplomático-interpretativo da edição, pois desenvolveram-se as abreviaturas e confeccionaramse notas de rodapé com informações elucidativas aos processos de decodificação e de interpretação do código linguístico. Para ilustrar o conservadorismo da edição, apresenta-se, acerca da figura 2, uma nota de rodapé em que há o seguinte esclarecimento para uma possível distração do escrevente: "Leia-se, na linha 9 da página 1 da carta setecentista oficial, < certifica $>$ por < cerifica $>$ ". 


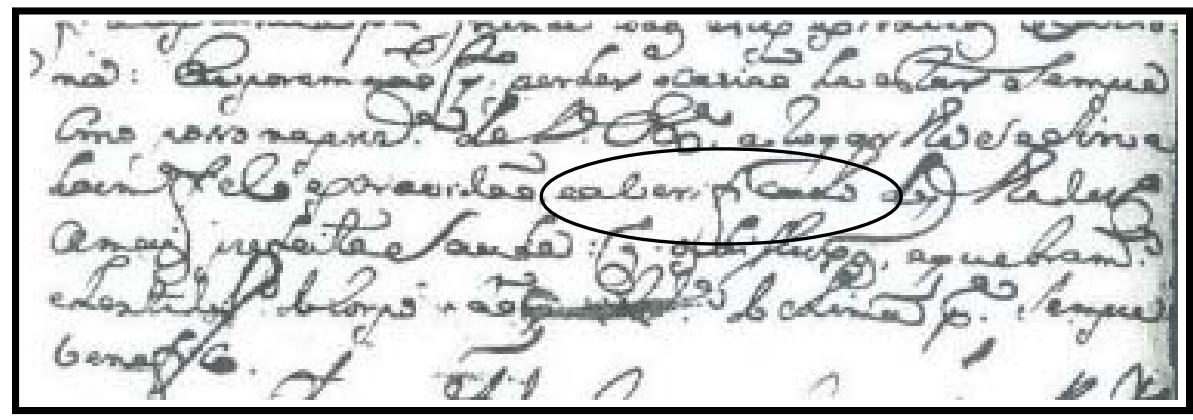

Figura 2: Trecho da carta de Joaquim Alves Meneses a Luís Antônio de Souza Botelho Mourão. Rio de Janeiro, 09.05.1768. Circulado nosso.

“(...)na: Eu porem não quero perder ocazião de estar Sempre | como posso naprezenca deVossa Excelência a Rogar lhe sesirva| daminhafiel escravidão, eacerificaLo deque lhedezejo | amais prefeitaSaude: que o difluxo, equebramento | eLentidão doCorpo São [ilegível] do cLima para Sempre | benefyco (...)”

Excerto 1: Trecho da carta de Joaquim Alves Meneses a Luís Antônio de Souza Botelho Mourão. Rio de Janeiro, 09.05.1768.

No excerto 1, tem-se uma evidência do rigor filológico da edição, a fim de apresentar, à comunidade acadêmica, uma leitura conservadora dos manuscritos que se preste aos estudos linguísticos.

\section{A caracterização das amostras do português no Brasil setecentista e oitocentista: as cartas particulares no Rio de Janeiro}

Conforme a discussão tecida por Barbosa ${ }^{16}$ acerca dos tipos de textos produzidos na segunda metade do século XVIII na América Portuguesa, entendem-se os textos da administração pública, da administração privada e os textos particulares como macro-categorias tipológicas.

\footnotetext{
${ }^{16}$ BARBOSA. Para uma história do português colonial.
} 
As cartas particulares escritas no Rio de Janeiro da segunda metade do século XVIII constituem-se como cópias de época ${ }^{17}$ de missivas particulares enviadas por um único remetente (Marquês do Lavradio) a diferentes destinatários: o padre Baptista, os seus filhos ${ }^{18}$ (Conde de Tarouca, Conde de Vila Verde), e os amigos (Antônio José de Miranda, João Henrique de Souza e Manoel da Cunha Menezes).

Com relação ao conjunto homogêneo de cartas pessoais do Marquês do Lavradio, admite-se que dificilmente se tenha acesso a um material de cunho pessoal produzido por um escritor culto no Brasil setecentista. Ressalte-se ainda a especificidade dessas missivas com relação ao grau de intimidade de relações interpessoais protagonizadas por um português, vice-rei do Brasil, na realidade sócio-histórica do Rio de Janeiro setecentista, como é possível constatar no excerto 2 :

“(...) MeuqueridoFilho, e Senhor domeuCoração; | Grande hé aconsolação, que tenho com asboas novas que Você me dá suas | porem dêvodizer=lhe averdade, eu menão Livro de cuidado, com quanto Você | não vive pormais mezes auzentedeLixboa (...)”

Excerto 2: Trecho da carta do Marquês do Lavradio ao seu filho, Conde de Tarouca. Rio de Janeiro, 17.11.1770.

\footnotetext{
${ }^{17}$ Afirma-se que tais cartas do Marquês do Lavradio, compiladas em dois códices (Códices 1095 e 1096 do Arquivo Nacional), constituam-se como cópias de época, pois no próprio códice, visualizado através do seu microfilme, há as seguintes informações: "Livro Copiador das cartas de Amizade do Marquês do Lavradio durante seu governo no Rio de Janeiro 1768-1772 e 1772-1776".

${ }^{18}$ Convém esclarecer que, no decorrer deste trabalho, a partir da reconstituição da árvore genealógica da família do Marquês do Lavradio, descobriu-se que o Conde de Tarouca e o Conde de Vila Verde não eram seus filhos consangüíneos, mas seus genros. Apesar de a relação consangüínea de pai e filho não existir verdadeiramente, as relações sociais travadas entre eles apresentam-se nas cartas em análise com esse sentido. O estudo de Marcotulio (A preservação das faces e a construção da imagem no discurso político do marquês do Lavradio) desobscurece tais relações interpessoais.
} 
Apresenta-se, a seguir a edição de uma carta pessoal do Marquês do Lavradio, produzida no Rio de Janeiro, a 06 de maio de 1774, ao seu filho, Conde de Vila Verde, agradecendo o recebimento de notícias do filho e dos netos e justificando o excesso de trabalho ser o motivo de não poder ser mais extenso na carta. Tem-se em exposição uma edição fac-similar diplomático-interpretativa, uma vez que o editor buscou intervir minimamente no texto tão somente no que se refere ao desenvolvimento de abreviaturas e de esclarecimentos sobre práticas linguístico-textuais peculiares a textos da época. Nesse sentido, tem-se, na carta em análise, o uso de reclamo, elucidado em nota de rodapé, como uma estratégia de enumeração de páginas de textos de sincronias passadas. Se hoje se usam números arábicos ou romanos para sequenciar as folhas do suporte da carta, àquela altura (séculos XVIII e XIX), usava-se também o reclamo. Trata-se de uma estratégia de coesão geral das informações sequencializadas no suporte que consiste na repetição do último item lexical ou de parte desse mesmo item lexical de uma determinada página na página seguinte, conforme se observa na figura 3 e excerto 3. 

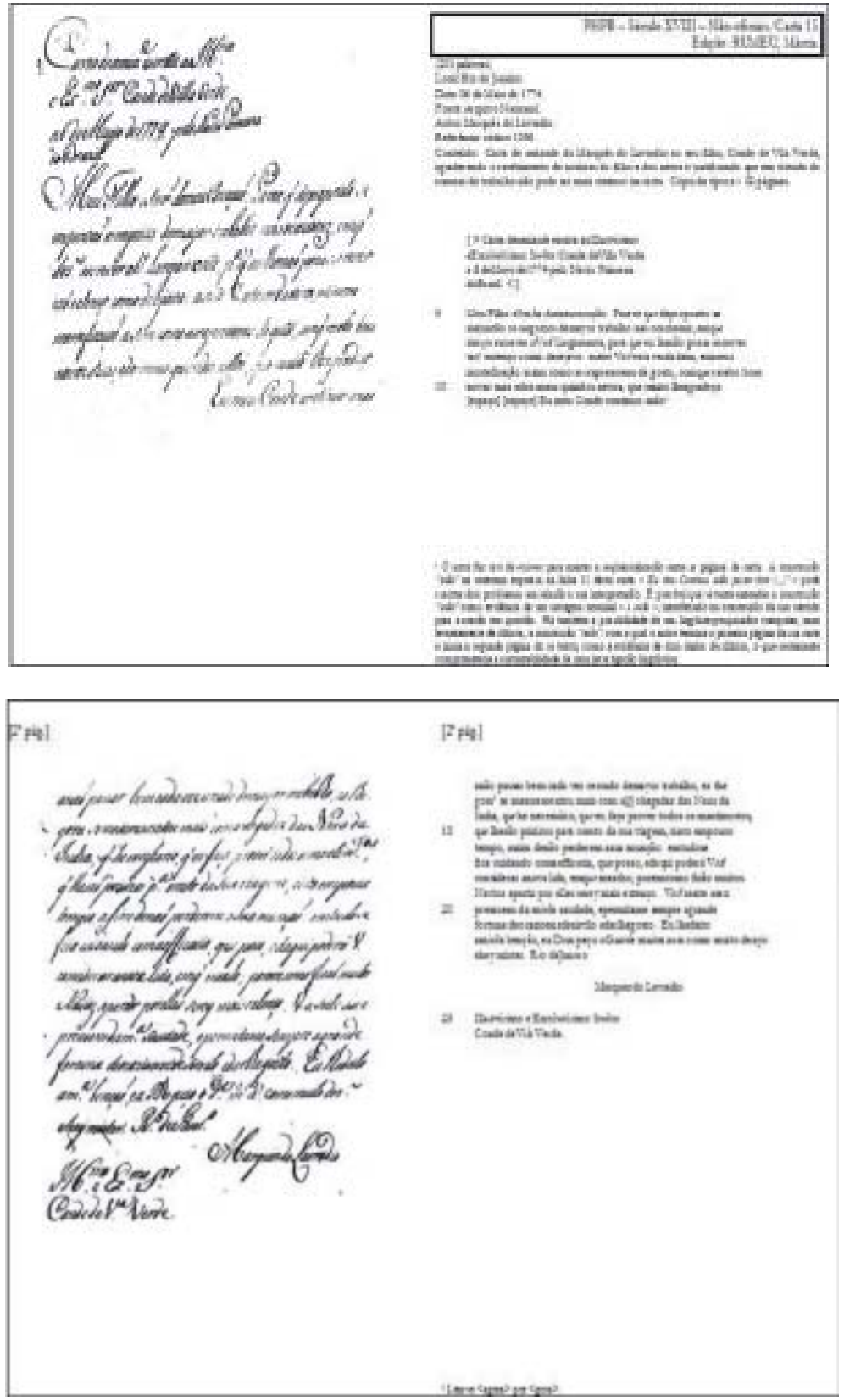

Figura 3: Carta de Marquês do Lavradio ao seu filho, Conde de Tarouca. Rio de Janeiro, 06.05.1774. 
$\mathrm{Na}$ carta em análise, a manutenção do encadeamento entre as páginas da missiva se dá pela repetição da última sequência de palavras da primeira página na segunda página, conforme se observa no excerto 3 .

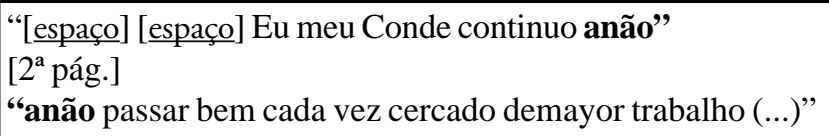

Excerto 3: Trecho da carta do Marquês do Lavradio ao seu filho, Conde de Tarouca. Rio de Janeiro, 06.05.1774. Negritos nossos.

Um tratamento descuidado poderia ser concedido ao dado de clítico que se deixa evidenciar na construção anão em continuo anão passar bem, repetida pelo Marquês do Lavradio, ao iniciar a segunda página da carta. Apesar de haver repetição do dado de clítico, esta ocorrência há de ser contabilizada apenas uma única vez para a análise da carta em questão. É possível ainda que, inadvertidamente, um leitor contemporâneo, ao se deparar com os dois vocábulos formais (anão: clítico+advérbio de negação), venha a interpretá-los como um único vocábulo formal - anão (substantivo) - expresso em forma de reclamo na passagem da primeira página para a segunda página da carta particular do Marquês do Lavradio (cf. excerto 3). Os reclamos funcionam, pois, como um mecanismo de enumeração que merece um comentário, na própria carta, em nota de rodapé, a fim de alertar o leitor para estratégias textuais utilizadas em documentos de sincronias passadas.

\section{A caracterização das amostras do português do Brasil oitocentista e novecentista: as cartas particulares}

O procedimento metodológico adotado por Lobo, ao editar cartas pessoais escritas pelas Clarissas do Convento de Santa Clara do Desterro, na Bahia do século XIX, foi o de construir uma sociolinguística histórica do PnB: 
Uma das vias possíveis para o estudo da constituição histórica do português brasileiro passaria, então, necessariamente pelo cuidadoso exame da história da transmissão de cada texto e da biografia do seu autor e, fundamentalmente, o seu desenvolvimento deveria apoiar-se em uma prática de análise em que a realidade lingüística portuguesa fosse motivo de cotejo sistemático ao longo dos séculos XVI, XVII, XVIII e XIX. ${ }^{19}$

A fim de subsidiar análises linguísticas elucidativas em relação à realização objetiva da norma culta escrita do PB que, segundo Pagotto ${ }^{20}$ foi habilmente fixada "à imagem e semelhança" do PE e amparada pela força do discurso científico, no Brasil do século XIX, entende-se que se faça necessária a edição de corpora representativos dessa modalidade linguística em terras d'aquém mar. Propõe-se, um maior grau de refinamento da amostra, ao editar os textos produzidos, no contexto sócio-histórico de fins do século XIX e da primeira metade do século XX, por informantes seguramente identificados em relação à sua origem brasileira e ao seu nível de escolaridade (culto). O conceito de culto para o período precisa ser obviamente redefinido. Consideram-se como cultos não só os missivistas que estudaram e se tornaram bacharéis (João Pedreira do Couto Ferraz, Jerônimo de Castro Abreu Magalhães, Fernando Pedreira de Abreu Magalhães, Jerônimo Pedreira de Abreu Magalhães - Pe. Jerônimo), mas também as filhas do casal de brasileiros Zélia Pedreira de Abreu Magalhães e Jerônimo de Castro Abreu Magalhães que se dedicaram à vida religiosa no interior dos conventos. Apesar de não haver indícios de que essas mulheres religiosas tenham chegado a concluir um curso superior, é possível assumilas como informantes cultas do PB devido à "bagagem intelectual" que adquiriram por terem nascido no seio de uma abastada família

\footnotetext{
${ }^{19}$ LOBO. Para uma sociolingüística bistórica do português no Brasil, p. 108.

${ }^{20}$ PAGOTTO. Norma e condescendência: ciência e pureza.
} 
brasileira oitocentista. No aconchego do lar da família Pedreira Ferraz-Magalhães, valorizava-se o ensino de línguas (inglês), das ciências, da música, da literatura, conforme Pedreira de Castro, ${ }^{21}$ difundindo-se, pois, a cultura num sentido mais amplo.

As missivas pessoais trocadas entre os membros da família Pedreira Ferraz-Magalhães expõem a intimidade de brasileiros letrados em intercâmbios comunicativos de informalidade caracterizados pela aproximação afetiva entre o remetente e o destinatário. Entende-se que os textos de circulação privada, segundo Barbosa, ${ }^{22}$ tais como as cartas pessoais da família Pedreira Ferraz-Magalhães, apresentem-se como os mais transparentes, como os mais livres da pressão prescritivista da norma padrão, em relação à explicitação de traços linguísticos da oralidade.

Ainda que, para Labov, ${ }^{23}$ o vernáculo das cartas, das peças teatrais e dos textos literários não expresse, com legitimidade, a norma objetivamente realizada no interior da comunidade linguística, só restam os registros escritos como reflexo da expressão do PB em sincronias pretéritas, conduzindo o linguista-pesquisador a um criterioso trabalho com a língua escrita. É claro que Labov tem razão, ao admitir que não há uma correspondência biunívoca entre a fala e a escrita, mas é possível detectar, na escrita cotidiana (familiar), reflexos da expressão falada da língua. Assim sendo, pinçaram-se trechos das cartas familiares em análise nos quais é possível entrever aspectos morfossintáticos que evidenciam traços de oralidade no registro escrito de falantes cultos do PB. Na produção escrita da família Pedreira Ferraz-Magalhães, foi possível observar a transparência dos seguintes traços morfossintáticos tais como a próclise, inclusive em início de sentença (cf. figuras 4 e 5), e a ausência de concordância verbal (cf. figuras 6 e 7). Acrescente-se que a colocação pronominal proclítica é característica do PB:

\footnotetext{
${ }^{21}$ PEDREIRA DE CASTRO. Zélia ou Irmã Maria do SS. Sacramento.

${ }^{22}$ BARBOSA. Para uma história do português colonial.

${ }^{23}$ LABOV. Principles of linguistic change: internal factors.
} 


\section{- Início da sentença com pronome oblíquo átono:}

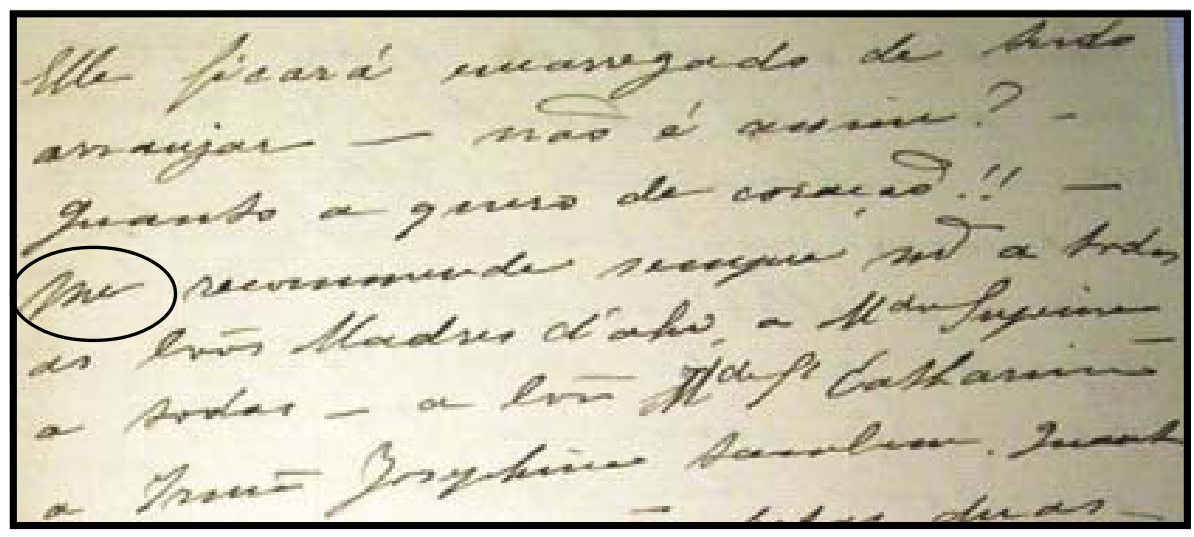

Figura 4: Trecho da carta de Maria Teresa de Jesus Bulhões Pedreira (Viscondessa de Duprat), com 59 anos, a sua filha. Rio de Janeiro, 20.11.1922. Circulado nosso.

“(...) Elle ficará encarregado de tudo | arranjar - não é assim? - | Quanto a quero de coração !! - | Me recommende sempre muito a todas | boãs Madres d'ahi a Madre Superiora |a todas - a boã Madre [Superiora] Catharina | a Irmã Josephina tambem. (...)”

Excerto 4: Trecho da carta de Maria Teresa de Jesus Bulhões Pedreira (Viscondessa de Duprat), com 59 anos, a sua filha. Rio de Janeiro, 20.11.1922. Negrito e sublinhado nossos.

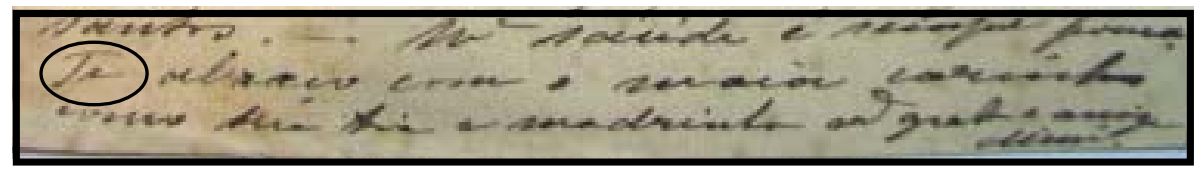

Figura 5: Trecho da carta de Maria Teresa de Jesus Bulhões Pedreira (Viscondessa de Duprat), com 49 anos, ao sobrinho Pe. Jerônimo. Rio de Janeiro, 16.10.1912. Circulado nosso.

“(...) Minha saude é sempre pouca. | Te abraço com o maior carinho | como tua tia e madrinha muito grata e amiga | Mimi”

Excerto 5: Trecho da carta de Maria Teresa de Jesus Bulhões Pedreira (Viscondessa de Duprat), com 49 anos, ao sobrinho Pe. Jerônimo. Rio de Janeiro, 16.10.1912. Negrito e sublinhado nossos 
- Ausência de concordância verbal:

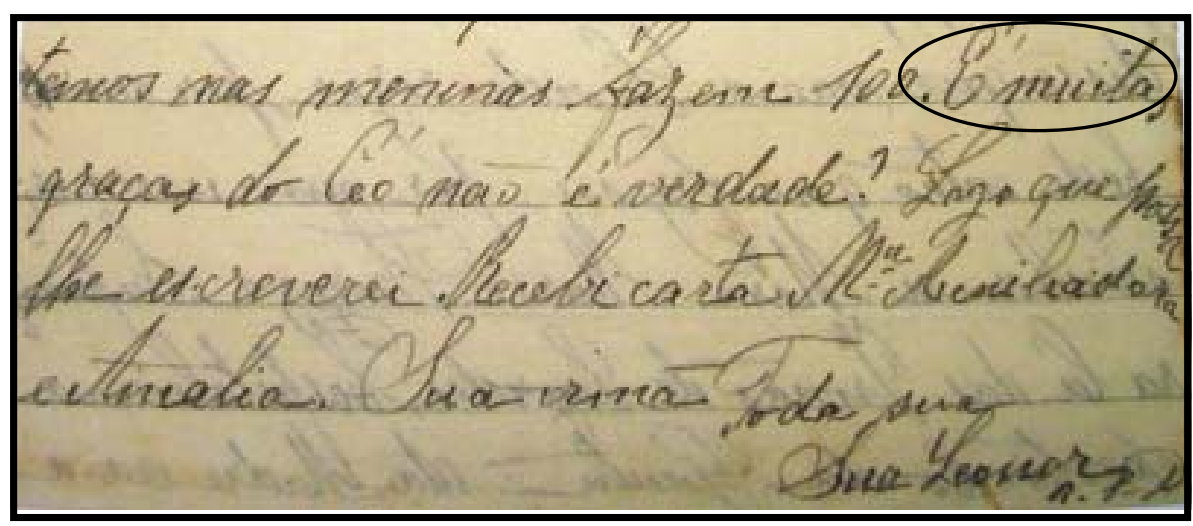

Figura 6: Trecho da carta de Maria Leonor, com 40 anos, a irmã Maria Joana (Jane). Pernambuco, Olinda, 11.07.1920. Circulado nosso.

“(...) temos nas meninas fazem 100. É muitas | graças do Céo não é verdade? Logo que possa | lhe escreverei Recebi carta Maria Auxiliadora | e Amalia. Sua irmã. Toda sua | Sua Leonor"

Excerto 6: Trecho da carta de Maria Leonor, com 40 anos, a irmã Maria Joana (Jane). Pernambuco, Olinda, 11.07.1920. Negrito e sublinhado nossos.

Costor conterclesoma que aneus invoror

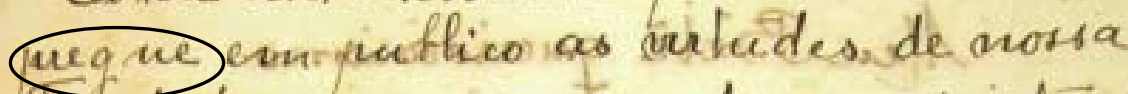

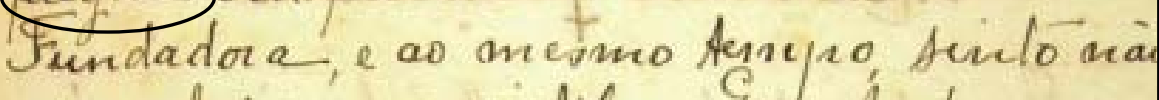
ustar ahi para assistil-o Gue fodos meno

Figura 7: Trecho da carta de Maria Rosa, com 56 anos, ao irmão (Bebê). La Plata, 05.04.1934. Circulado nosso

“[espaço] Estou contentissima que meus irmãos | pregue em publico as virtudes de nossa | Fundadora, e ao mesmo tempo, sinto não | estar ahi para assistil-o. (...)”

Excerto 7: Trecho da carta de Maria Rosa, com 56 anos, ao irmão (Bebê). La Plata, 05.04.1934. Negrito e sublinhado nossos. 
Editaram-se cento e setenta cartas de teor pessoal confeccionadas por informantes cultos, nascidos no Rio de Janeiro e integrantes das ilustres famílias Pedreira Ferraz-Magalhães, que se corresponderam entre 1877 e 1948 . A conservadora edição facsimilar diplomático-interpretativa de tais cartas, organizada a partir da identificação do perfil sócio-histórico dos missivistas, permitirá desvendar, tendo em vista o caráter pessoal das correspondências, aspectos rotineiros da vida cotidiana brasileira, de fins do século XIX e no alvorecer do século XX. Trata-se de um material sui generis para o reconhecimento da história da vida privada de uma família brasileira nascida no Rio de Janeiro que circulou da capital carioca para o interior e por outros espaços sócio-geográficos dentro e fora do Brasil. Uma família religiosa que, apesar dos deslocamentos advindos da pressão social da vida adulta, se manteve unida pelas cartas ativas e passivas trocadas entre seus membros ao longo das suas vidas.

É interessante observar o caráter familiar da carta de João Pedreira do Couto Ferraz a sua neta, Iza (Maria Elisa), em que o avô a parabeniza por já ter sido alfabetizada e pela sua bela caligrafia, como se observa no excerto 8 , em consonância com o $1^{\circ}$ e o $2^{\circ}$ parágrafos da missiva apresentada na figura 08 .

"Minha mimosa Iza

Foi com muito prazer que li a | tua cartinha. Então ?! Já a | minha filhinha tão mocinha | escreve que se póde ler com | acerto e bôa lettra. Bravo! Em tudo has de parecer te com a | tua inimitavel Mãe.”

Excerto 8: Trecho da carta de João Pedreira do Couto Ferraz, com 69 anos, a sua neta Maria Elisa (Isa).Rio de Janeiro, 08.07.1895. 


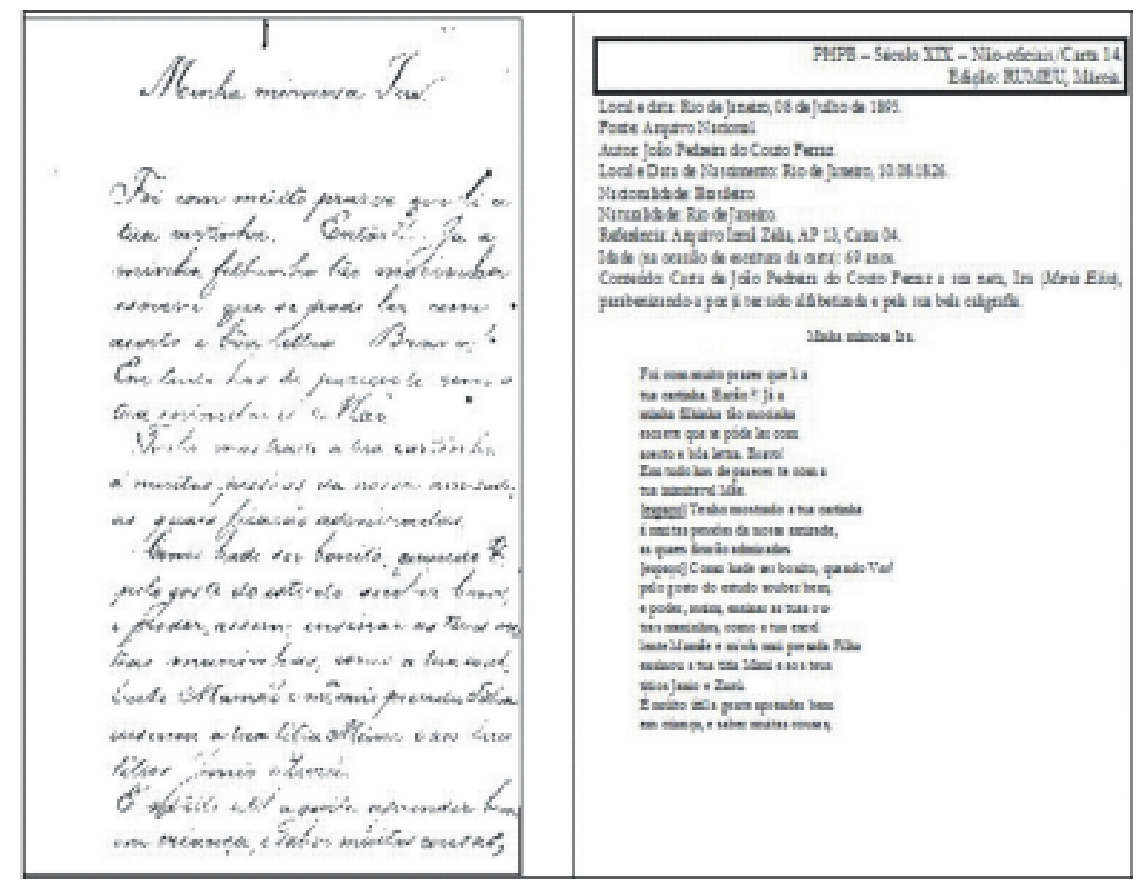

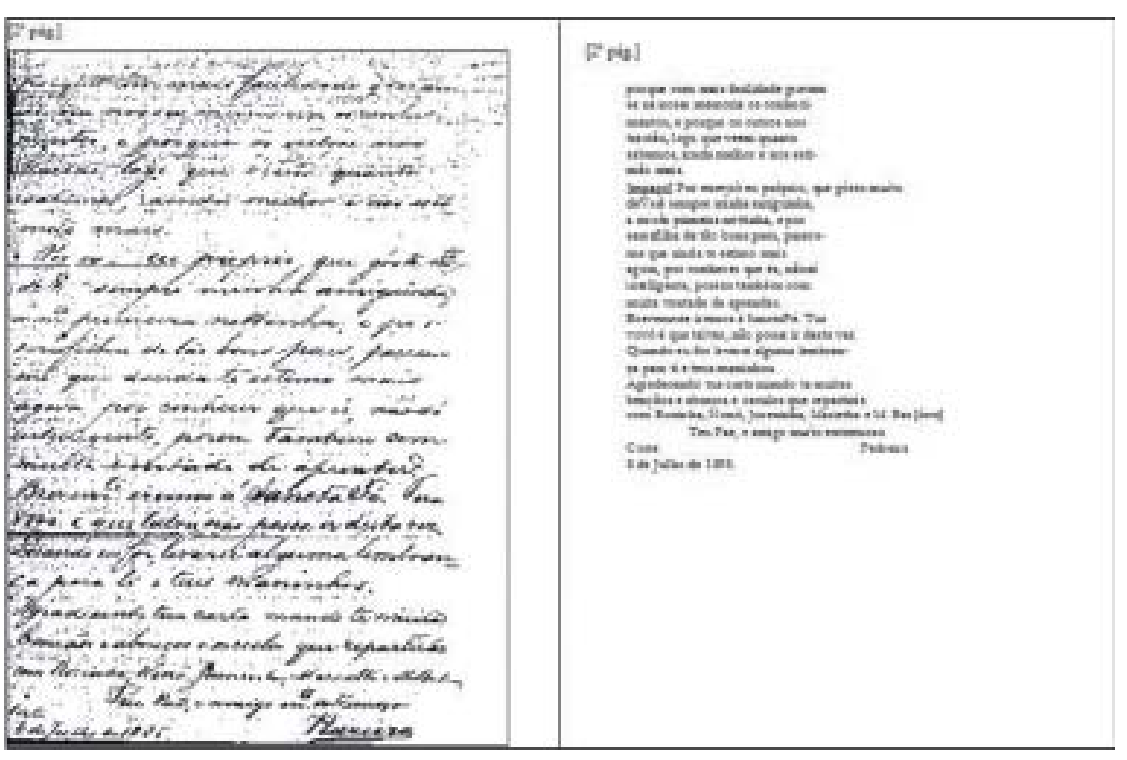

Figura 8: Carta de João Pedreira do Couto Ferraz, com 69 anos, a sua neta Maria Elisa (Isa). Rio de Janeiro, 08.07.1895. 
A partir dessas amostras que estarão disponíveis à comunidade científica, através da edição fac-similar diplomáticointerpretativa em análise, é possível detectar as redes sóciofamiliares das quais participavam seus membros, o comportamento sócio-linguístico de uma família cristã na Corte carioca e, ainda, o perfil sócio-cultural da mulher, principalmente a religiosa, no início do período republicano num Brasil em transformação.

\section{Proposta metodológica para os estudos linguísticos acerca do processo de formação do português brasileiro}

À luz do desejo de construção de uma sociolinguística histórica do PnB implementada por Lobo, ${ }^{24}$ buscou-se organizar uma amostra de cartas pessoais em que fosse possível desvendar majoritariamente onde, quando, por quem e para quem foram confeccionadas as missivas em análise. Acredita-se que a "arte de fazer o melhor uso de maus dados”, nos termos de Labov ${ }^{25}$ deve ser o princípio orientador não só de trabalhos linguísticos com dados sincrônicos, mas também com dados diacrônicos, segundo Romaine. ${ }^{26} \mathrm{O}$ desejo de descrever e de analisar a expressão vernácula da língua em sincronias passadas requer que se atente para o "problema dos filtros" que, por sua vez, deve constituir uma preocupação pertinente tanto aos estudos de língua escrita, quanto aos de língua falada. ${ }^{27}$

Para se libertar da obscuridade do trabalho com realidades linguísticas muito distantes da sua, cabe ao linguista-pesquisador "expurgar" da sua amostra as possíveis inadequações que um corpus de língua escrita em sincronias passadas pode oferecer,

\footnotetext{
${ }^{24}$ LOBO. Para uma sociolingüística bistórica do português no Brasil.

${ }^{25}$ LABOV. Principles of linguistic change: internal factors, p. 11.

${ }^{26}$ ROMAINE. Socio-bistorical linguistics.

${ }^{27}$ ROMAINE. Socio-bistorical linguistics apud LOBO. Para uma sociolingüística bistórica do português no Brasil, p. 99.
} 
tais como os elencados por Labov: ${ }^{28}$ hipercorreção, mistura dialetal e "erros" do escriba. É, portanto, tarefa do linguista criar e dosar o grau de refinamento metodológico necessário para distinguir, com clareza, o que é traço específico do vernáculo da língua do que é expressão idiossincrática do autor. Nesse sentido, para a confecção da edição das cartas brasileiras a partir da perspectiva de construção de uma sociolinguística do português não só no Brasil, como propõe Lobo ${ }^{29}$ mas também do Brasil, adotaram-se os seguintes procedimentos metodológicos:

$\sqrt{ }$ A identificação do perfil social dos informantes (missivistas) de sincronias passadas do português

Um dos aspectos apontados por Labov ${ }^{30}$ como responsável por tornar deficitário o estudo linguístico sob uma perspectiva diacrônica é a difícil identificação do perfil social dos autores dos textos. Conseguiu-se reconstituir, para essas cartas familiares, a história de vida de todos os autores das cento e setenta cartas editadas. Os missivistas da família Pedreira Ferraz-Magalhães, cuja biografia foi revelada com a consulta a duas obras sobre a vida da Irmã Zélia, produzidas pelo seu próprio filho, ${ }^{31}$ apresentam as suas fichas de identificação confeccionadas, nos moldes de Lobo, ${ }^{32}$ com sucesso.

$\sqrt{ }$ O gênero dos textos que compóem os corpora para estudos diacrônicos do português

A fim de que o vernáculo da língua possa saltar aos olhos do linguista-pesquisador com um maior grau de clareza e

\footnotetext{
${ }^{28}$ LABOV. Principles of linguistic change: internal factors, p. 11.

${ }^{29}$ LOBO. Para uma sociolingüística bistórica do português no Brasil.

${ }^{30}$ LABOV. Principles of linguistic change: internal factors, p. 11.

${ }^{31}$ PEDREIRA DE CASTRO. Zélia ou Irmã Maria do SS. Sacramento; PEDREIRA DE CASTRO Segundo Livro de Zélia (Irmã Maria do Santíssimo Sacramento).

${ }^{32}$ LOBO. Para uma sociolingüística bistórica do português no Brasil.
} 
fidedignidade a uma realidade linguística passada, há de se atentar para a produção escrita em sincronias passadas, buscando textos mais "soltos" em relação ao seguimento da norma padrão. A opção pelo trabalho com cartas pessoais somente trocadas entre os entes da mesma família (a família Pedreira Ferraz-Magalhães) em estanques lapsos de tempo se dá por se tratar de um tipo de texto que expressa, com um menor grau de formalismo, a subjetividade das ideias compartilhadas entre os interlocutores. Acrescente-se a isso o fato de as cartas pessoais em análise evidenciarem a intimidade das relações familiares entre pais e filhos, entre irmãos, entre tios e sobrinhos e entre amigos, no contexto sócio-histórico e linguístico de fins do século XIX e da primeira metade do século XX. A construção de uma sociolinguística histórica do PB, nos moldes de Lobo, ${ }^{33}$ com base na reconstituição da história de vida dos informantes (missivistas), corrobora o controle das díades que sustentam a dinâmica das cartas pessoais trocadas no seio da família Pedreira Ferraz-Magalhães. Nas cartas editadas, as díades controladas evidenciam as relações familiares travadas entre pais e filhos, entre avô e netos, entre irmãos, entre tia e sobrinhos e entre amigos como remetentes e destinatários das missivas da família Pedreira Ferraz-Magalhães.

\section{$\sqrt{ }$ A preferência por manuscritos autógrafos}

A necessidade de construção de uma filologia de textos escritos no Brasil defendida por Lobo constituiu-se como o parâmetro desta proposta metodológica voltada para o trabalho com textos escritos em sincronias passadas.

Exige-se do lingüista historiador da língua, como de qualquer outro historiador, a capacidade de reconstruir e interpretar eventos passados. (...) Do fato de lidar com textos escritos, decorre ainda uma exigência

\footnotetext{
${ }^{33}$ LOBO. Para uma sociolingüística histórica do português no Brasil.
} 
preliminar, a de que - caso não seja, ele próprio, também filólogo - disponha de conhecimentos filológicos, a fim de que saiba distinguir nos hábitos de escrita do passado os que têm significado, do ponto de vista lingüístico, dos que não têm, e a fim, também, de que os resultados da sua análise não sejam de pronto descartados, em virtude do pecado original da má constituição de corpora a partir de textos não submetidos ao crivo de uma análise filológica. ${ }^{34}$

O estudo de realidades linguísticas distantes requer a busca por argumentos que legitimem o texto como um fiel representante de uma dada sincronia passada. Assim sendo, faz-se necessário que se volte o foco para o tratamento filológico dado às amostras que sustentará a análise sociolinguística. O ideal é que a amostra seja composta por vários textos, permitindo o cotejo e a separação das cartas escritas e assinadas pelo missivista (cartas autógrafas), das outras cartas que podem ter sido escritas por um escriba (escrevente) e assinadas pelo remetente ou que podem ter sido escritas e assinadas por um escriba (cartas apógrafas)..$^{35} \mathrm{O}$ reconhecimento do tipo de letra com que a missiva foi escrita e do tipo de assinatura do redator constituem os traços formais que permitem entrever se o documento foi produzido e assinado pelo mesmo informante-escrevente.

$\mathrm{Na}$ amostra de missivas da coleção Irmã Zélia, o acentuado número de cartas legitimou o cotejo e a análise entre tais textos, fundamentando a constatação segura de que todas as cartas são autógrafas, isto é, produzidas e assinadas pelo mesmo missivista. Tal fato constituiu, indubitavelmente, um fator positivo para esta análise, pois se tem certeza sobre a mão que escreve as missivas da família Pedreira Ferraz-Magalhães: são mãos brasileiras que confeccionam cartas cotidianamente (numa explícita manifestação

\footnotetext{
${ }^{34}$ LOBO. Para uma sociolingüística bistórica do português no Brasil, p. 104.

${ }^{35}$ LOBO. Para uma sociolingüística bistórica do português no Brasil, p. 148.
} 
de escrita informal) em situações linguísticas de intimidade entre os familiares.

$\sqrt{ }$ A relevância da confecção de edições conservadoras nos estudos diacrônicos do PB

Para Barbosa, a construção de corpora confiáveis ao estudo linguístico do $\mathrm{PB}$, tanto deve voltar-se para reconstrução do contexto sócio-bistórico daquela sincronia passada, quanto para a compreensão do contexto de escritura dos textos a serem editados, a fim de expor, à comunidade acadêmica, uma amostra que seja reflexo expressivo de um dado momento histórico-social:

Nessa altura em que se debruçam por sobre os diversos escritos produzidos na América Portuguesa pesquisadores tanto de linhas empiricistas, quanto de mentalistas, tornou-se imprescindível editarem-se textos em prosa não literária que não apresentem semelhantes limitações às diversas abordagens possíveis com os dados deles oriundos. Mais que isso, edições que avancem ao máximo na descrição, portanto, não só do contexto sócio-histórico do texto, mas na das condições de produção, relação entre emissor e receptor, modalidade, estilo etc., tornam-se imperativas para estabelecer confiabilidade e fidedignidade ao material posto à disposição da comunidade acadêmica dedicada às questões acerca da mudança lingüística. ${ }^{36}$

Optou-se por apresentar as cartas pessoais elaboradas pelos brasileiros cultos da família Pedreira Ferraz-Magalhães a partir da sua reprodução em fac-símile para que o leitor possa checar a leitura do editor, confirmando-a ou infirmando-a. A adoção de uma leitura conservadora do manuscrito pressupõe o total respeito à grafia, à pontuação e a todas às práticas textuais

\footnotetext{
${ }^{36}$ BARBOSA. Para uma bistória do português colonial, p. 106; grifo do autor.
} 
identificáveis como peculiares aos textos produzidos naquelas sincronias passadas (séculos XIX e XX), comprometendo-se em não modernizá-los em aspecto linguístico algum. Uma vez adotado o parâmetro de transcrição conservadora das cartas oitocentistas e novecentistas, decidiu-se também apresentá-las, à comunidade acadêmica, através de uma edição diplomático-interpretativa, conforme definida por Spina. ${ }^{37}$

Enfim, acredita-se que o caráter informal das cartas trocadas entre entes da família Pedreira Ferraz-Magalhães possa ser corroborado pelo seguinte comentário produzido pela informante brasileira Maria Rosa no fim de uma de suas missivas: "Pasei a manhã muito agradavel escrevendo a Você parece que estavas aqui". Nessa carta, Maria Rosa, ao escrever ao irmão, em 1948, também entende a missiva como um diálogo por escrito, corroborando a percepção de Cícero, entre 103 e 43 a.c., acerca do caráter sui generis da carta que é o de aproximar as pessoas através do discurso escrito:

$\mathrm{Eu}$, apesar de nada ter para te escrever, ainda assim escrevo, pois parece que falo contigo. (Epistulae ad atticum $(12,53))$

Eu te vi todo em tua carta. (Epistulae ad familiares $(2,4,1 ; 4,13,1 ; 6,10,4))^{38}$

\section{Considerações finais}

Ao considerar a relevância da contribuição filológica a nortear a confecção de uma sociolinguística histórica do PnB e $\mathrm{PB}$, comprova-se a necessidade de edições de manuscritos de sincronias passadas fazerem-se na forma de uma edição fac-similar diplomático-interpretativa. Acrescente-se ainda que essa edição deve ser criteriosamente organizada com o desenvolvimento dos

${ }^{37}$ SPINA. Introdução à edótica, p. 79.

${ }^{38}$ Apud TIM. A arte de escrever cartas, p. 21. 
índices abreviativos e a confecção de observações em notas de rodapé de modo a otimizar a decodificação do código escrito e a sua interpretação em sincronias passadas, contribuindo para uma leitura conservadora do manuscrito não-literário. Nesse sentido, a partir do rigor filológico de reconstituição e conservação da produção escrita portuguesa por terras d'aquém mar em sincronias passadas, acredita-se ser possível avançar nas investigações sobre a história do processo de formação do PB.

\begin{abstract}
Resumé: Le but de cet article est de présenter le processus de formation des corpora pour l'étude du portugais au Brésil et du Brésil, à partir de l'édition de lettres manuscrites fac-similées diplomatico-interprétatives dans la seconde moitié du XVIII ${ }^{\text {ème }}$ siècle, tout au long du $\mathrm{XIX}^{\text {ème }}$ siècle et dans la première moitié du $\mathrm{XX}^{\text {ème }}$ siècle. L'édition de l'échantillon du portugais au Brésil est composée de 60 lettres manuscrites écrites par des Brésiliens et des Portugais, à Rio de Janeiro, au XVIII ${ }^{\text {ème }}$ et au XIX ${ }^{\text {ème }}$ siècle. En ce qui concerne l'échantillon du portugais du Brésil, il réunit 170 lettres manuscrites des membres de la famille brésilienne Pedreira FerrazMagalhães, nés à Rio de Janeiro, entre 1877 et 1948.
\end{abstract}

Mots-clés: Critique textuelle; édition de lettres manuscrites; portugais au Brésil; portugais du Brésil.

\title{
Referências
}

BARBOSA, A. G. Para uma bistória do português colonial: aspectos linguísticos em cartas de comércio. 1999. Tese (Doutorado em Língua Portuguesa) - Faculdade de Letras, UFRJ, Rio de Janeiro.

CAMBRAIA, C. N. Introdução à crítica textual. São Paulo: Martins Fontes, 2005.

CASTRO, I. Para uma história do português clássico. In: DUARTE, I.; LEIRIA, I. (Orgs.) Actas do Congresso Internacional sobre o Português. Lisboa: Colibri, 1996. p. 135-150. 
CUnHA, A. G.; CAMBRAiA, C. N.; MEgALE, H. A carta de Pero Vaz de Caminha. São Paulo: Humanitas, 1999.

LABOV, W. Principles of linguistic change: internal factors. Cambridge: Blackwell Publishers, 1994. Vol. 1.

LOBO, T. C. F. Para uma sociolinguística bistórica do português no Brasil: edição filológica e análise linguística de cartas particulares do Recôncavo da Bahia, século XIX. 4 volumes. 2001. Tese (Doutorado em Filologia e Língua Portuguesa) - Faculdade de Filosofia, Letras e Ciências Humanas da USP. São Paulo, Volume II.

Depoimento sobre a constituição de um corpus diacrônico do português brasileiro - Bahia. In: CASTILHO, A. T. (Org.) Para a bistória do português brasileiro (volume I: primeiras idéias). São Paulo: Humanitas, 1998. p. 171-195.

MARCOTULIO, L. L. A preservação das faces e a construção da imagem no discurso político do marquês do Lavradio: as formas de tratamento como estratégias de atenuação da polidez linguística. 2008. Volumes I e II. Dissertação (Mestrado em Língua Portuguesa) - Faculdade de Letras, UFRJ, Rio de Janeiro.

OLIVEIRA, K. Textos escritos por africanos e afro-descendentes na Babia do século XIX: fontes do nosso latim vulgar? 4 volumes. 2003. Dissertação (Mestrado em Letras) - Faculdade de Letras, UFBA, Salvador.

PAGOTTO, E. G. Norma e condescendência: ciência e pureza. Línguas e Instrumentos Linguísticos, São Paulo, n. 2, p. 49-68, 1999.

PEDREIRA DE CASTRO, Pe. J. Zélia ou Irmã Maria do SS. Sacramento: vida exemplar de uma mãe cristã, que terminou seus dias junto a Jesus Sacramentado. 7. ed. Petrópolis: Vozes, 1960.

Segundo Livro de Zélia (Irmã Maria do Santíssimo Sacramento): seus escritos espirituais, cartas e exemplos. Petrópolis: Vozes. 1943.

ROMAINE, S. Socio-bistorical linguistics: it's status and methodology. Cambridge: Cambridge University Press, 1982.

RUMEU, M. C. de B. A implementação do 'você' no português brasileiro oitocentista e novecentista: um estudo de painel. 2008. 2 volumes. Tese (Doutorado em Língua Portuguesa) - Faculdade de Letras, UFRJ. Rio de Janeiro. 
RUMEU, M. C. de B. Para uma história do português no Brasil: formas pronominais e nominais de tratamento em cartas setecentistas e oitocentistas. 2004. 2 volumes. Dissertação (Mestrado em Língua Portuguesa) - Faculdade de Letras, UFRJ, Rio de Janeiro.

SPINA, S. Introdução à edótica: crítica textual. São Paulo: Cultrix/ Edusp, 1977 [2. ed. rev. e atual. São Paulo: Ars Poetica/Edusp, 1994].

TIM, E. (Org.). A arte de escrever cartas: Anônimo de Bolonha, Erasmo de Rotterdam, Justo Lípsio. Campinas: Editora da UNICAMP, 2005. 